\title{
30-day morbidity and mortality of sleeve gastrectomy, Roux-en-Y gastric bypass and one anastomosis gastric bypass: a propensity score-matched analysis of the GENEVA data
}

\author{
Rishi Singhal $\mathbb{D}^{1,176}{ }^{凶}$, Victor Roth Cardoso ${ }^{2,3,176}$, Tom Wiggins ${ }^{1,176}$, Jonathan Super ${ }^{4}$, Christian Ludwig ${ }^{5}$, Georgios V. Gkoutos ${ }^{2,3,6,7}$,
} Kamal Mahawar ${ }^{8}$ and GENEVA Collaborators*

(c) The Author(s) 2021

BACKGROUND: There is a paucity of data comparing 30-day morbidity and mortality of sleeve gastrectomy (SG), Roux-en-Y gastric bypass (RYGB), and one anastomosis gastric bypass (OAGB). This study aimed to compare the 30-day safety of SG, RYGB, and OAGB in propensity score-matched cohorts.

MATERIALS AND METHODS: This analysis utilised data collected from the GENEVA study which was a multicentre observational cohort study of bariatric and metabolic surgery (BMS) in 185 centres across 42 countries between 01/05/2022 and 31/10/2020 during the Coronavirus Disease-2019 (COVID-19) pandemic. 30-day complications were categorised according to the Clavien-Dindo classification. Patients receiving SG, RYGB, or OAGB were propensity-matched according to baseline characteristics and 30-day complications were compared between groups.

RESULTS: In total, 6770 patients (SG 3983; OAGB 702; RYGB 2085) were included in this analysis. Prior to matching, RYGB was associated with highest 30-day complication rate (SG 5.8\%; OAGB 7.5\%; RYGB 8.0\% $(p=0.006)$ ). On multivariate regression modelling, Insulin-dependent type 2 diabetes mellitus and hypercholesterolaemia were associated with increased 30-day complications. Being a non-smoker was associated with reduced complication rates. When compared to SG as a reference category, RYGB, but not OAGB, was associated with an increased rate of 30-day complications. A total of 702 pairs of SG and OAGB were propensity score-matched. The complication rate in the SG group was $7.3 \%(n=51)$ as compared to $7.5 \%(n=53)$ in the OAGB group ( $p=0.68$ ). Similarly, 2085 pairs of SG and RYGB were propensity score-matched. The complication rate in the SG group was $6.1 \%(n=127)$ as compared to $7.9 \%(n=166)$ in the RYGB group $(p=0.09)$. And, 702 pairs of OAGB and RYGB were matched. The complication rate in both groups was the same at $7.5 \%(n=53 ; p=0.07)$.

CONCLUSIONS: This global study found no significant difference in the 30-day morbidity and mortality of SG, RYGB, and OAGB in propensity score-matched cohorts.

International Journal of Obesity (2022) 46:750-757; https://doi.org/10.1038/s41366-021-01048-1

\section{INTRODUCTION}

Sleeve gastrectomy (SG), Roux-en-Y gastric bypass (RYGB), and one anastomosis gastric bypass (OAGB) are the three commonest bariatric procedures worldwide [1]. There is currently no randomised controlled trial $(\mathrm{RCT})$ comparing these three procedures in the scientific literature. There are several RCTs comparing two of these three procedures $[2,3]$ but they were not powered to evaluate differences in morbidity or mortality.

30-day morbidity and mortality is a recognised outcome measure for the evaluation of surgical safety and has been used in surgical literature for several decades [4]. There are large studies comparing 30-day morbidity and mortality of RYGB and SG. Alizadeh et al. [5] reported from an analysis of Metabolic and Bariatric Surgery Accreditation and Quality Improvement Program (MBSAQIP) data in the United States that RYGB was associated with higher 30 -day morbidity $(4.4 \%$ vs $2.3 \%$; adjusted odds ratio (AOR) $0.53 ; p<0.01)$ and 30 -day mortality $(0.2 \%$ vs $0.1 \%$; AOR 0.58 ; $p=0.07$ ) in comparison with SG. However, there is no large data in the scientific literature comparing 30-day morbidity and mortality of SG and OAGB or RYGB and OAGB.

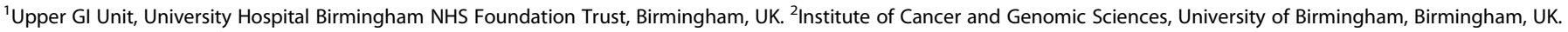

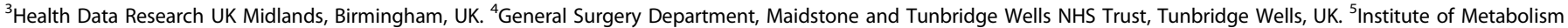

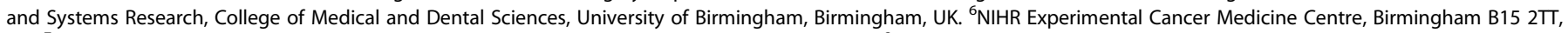

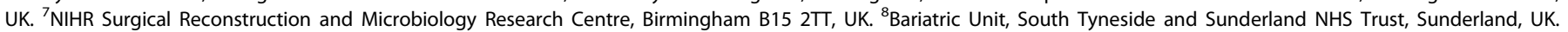
${ }^{176}$ These authors contributed equally: Rishi Singhal, Victor Roth Cardoso, Tom Wiggins. ${ }^{*}$ A full list of author affiliations appears at the end of the paper.

凶email: singhal_rishi@hotmail.com
} 
Notwithstanding the lack of such large data, these direct database comparisons are often flawed due to significant differences in the baseline population. Propensity score matching is a valid tool for comparing non-randomised populations by matching them for confounding variables [6]. To the best of our knowledge, there is only one published study comparing 30-day morbidity and mortality of SG and RYGB [7]; and one comparing RYGB and OAGB [8] in propensity score-matched populations. Both of these studies emanate from the MBSAQIP database. In their study, Kapur et al. [7] found lower adverse events with SG in comparison with RYGB. However, the study by Docimo et al. [8] comparing the 30-day morbidity of OAGB and RYGB had too few patients to be meaningful. It is probably because the MBSAQIP database is not likely to have large numbers of OAGB, a procedure not endorsed by the American Society for Metabolic and Bariatric Surgery.

Global 30-day outcomes after bariatric surgEry duriNg thE COVID-19 pAndemic (GENEVA) study [9] is a large, multinational, observational study evaluating 30-day morbidity and mortality of bariatric and metabolic surgery (BMS) during the Coronavirus Disease-2019 (COVID-19) pandemic. The global reach of the study, a large number of patients, and significant numbers of OAGB procedures submitted to this study present a unique opportunity to compare 30-day morbidity and mortality of SG, OAGB, and RYGB in propensity score-matched cohorts.

\section{METHODS}

\section{Study design and population}

The GENEVA study is an international, multicentre, observational cohort study of BMS performed between $1 / 05 / 2020$ and 31/10/2020 [9]. The current study included all consecutive patients who underwent a primary SG or RYGB or OAGB during this period. Detailed methods have been published previously [9-11]. Data collection included patients' demographics, details of surgery performed, and in-hospital as well as 30-day morbidity and mortality. Complications were categorised using the Clavien-Dindo (CD) Classification system for reporting surgical complications [12].

\section{Statistical methods}

Only patients with a complete data entry were included in the analysis. Continuous data were presented as median and interquartile range. Frequencies were used to summarise categorical variables. To examine differences between the three individual procedure types, the Fisher's exact test was used for categorical variables and Kruskal-Wallis analysis of variance testing for continuous variables.
Propensity score matching was completed in a step-wise fashion. Pairwise propensity matching was performed to robustly assess the quality of matching. Standardized mean difference (SMD) was used statistic to examine the balance of covariate distribution between treatment groups. Patients were matched using the following features: sex, Type 2 diabetes mellitus (T2DM) status (No diabetes; diet controlled; oral hypoglycaemics; insulin therapy), hypertension, hypercholesterolaemia, obstructive sleep apnoea, smoking status, age, and baseline body mass index (BMI).

The patients were matched against individuals that had other surgeries using the "nearest" method which utilises a greedy search to match each sample with their nearest neighbour. The distance was calculated using the Mahalanobis distance, which estimates the distribution closest for each point [13]. This procedure was performed in $R$ ( $R$ Core Team 2021) using the Matchlt package $[14,15]$. The outcome variable was the presence of a complication at 30-days follow-up.

Multivariate analysis was performed to strengthen the resulting statistics from univariate analysis, correcting the influence of each variable on the outcome measured. Multivariate models were created using all the variables used for propensity score matching plus ethnicity (white ethnicity vs other ethnic groups), presence of any co-morbidity, and other unspecified co-morbidity (other than those listed above). Patients were then analysed using a generalised linear model in R (R Core Team 2021) [14].

\section{RESULTS}

A total of 470 surgeons from 179 centres in 42 countries submitted data on 7092 adult patients who underwent primary BMS between 1st May 2020 and 31st October 2020 at the participating centres. Of these, complete 30-day morbidity and mortality data were available for $7084(99.88 \%)$ by the 10th of December 2020.

\section{Basic demographics}

Of the 7084 patients, 300 patients underwent other procedures and were excluded. A further 14 patients were excluded due to missing values. Complete data were available for a total of 6,770 patients who underwent a primary SG or RYGB or OAGB (SG $n=$ 3983; RYGB $n=2085$, OAGB $n=702$ ). Demographic details for all the patients, who underwent any of these three primary procedures are included in Table 1. There were multiple significant differences in baseline demographics between the three groups as detailed in Table 1. RYGB patients were significantly older than patients in the other two cohorts while patients receiving OAGB were more likely to suffer from co-morbidities (Table 1). Patients undergoing SG had the lowest rate of each of these co-morbidities as detailed in Table 1.

Table 1. Baseline demographics of all patients undergoing a primary SG or RYGB or OAGB (unmatched cohort-14 patients excluded due to incomplete data).

\begin{tabular}{|c|c|c|c|c|}
\hline Characteristic & SG $(n=3983)$ & OAGB $(n=702)$ & RYGB $(n=2085)$ & $p$ value \\
\hline Median Age (years) & $38(29.2-47.0)$ & $40(33.0-50.0)$ & $43(34-52)$ & $<0.001^{\mathrm{a}}$ \\
\hline Median BMI $\left(\mathrm{kg} / \mathrm{m}^{2}\right)$ & $41.91(38.14-46.77)$ & $43.11(38.87-48.77)$ & $41.87(38.67-45.73)$ & $<0.001^{a}$ \\
\hline Sex (Female) & $2883(72 \%)$ & $496(71 \%)$ & $1589(76 \%)$ & $<0.001^{\mathrm{b}}$ \\
\hline Non-Smoker & $2906(73 \%)$ & $528(75 \%)$ & 1502 (72\%) & $0.24^{b}$ \\
\hline T2DM & $649(16 \%)$ & $229(33 \%)$ & $484(23 \%)$ & $<0.001^{\mathrm{b}}$ \\
\hline Diet controlled & $204(5 \%)$ & 74 (11\%) & 107 (5\%) & \\
\hline Oral hypoglycaemics & $370(9 \%)$ & $106(15 \%)$ & $277(13 \%)$ & \\
\hline Insulin therapy & $75(2 \%)$ & $49(7 \%)$ & $100(5 \%)$ & \\
\hline Hypercholesterolaemia & $763(19 \%)$ & $224(32 \%)$ & $476(23 \%)$ & $<0.001^{b}$ \\
\hline Hypertension & $1101(28 \%)$ & $272(39 \%)$ & $720(35 \%)$ & $<0.001^{b}$ \\
\hline Obstructive sleep apnoea & $975(24 \%)$ & $229(33 \%)$ & $517(25 \%)$ & $<0.001^{b}$ \\
\hline
\end{tabular}

SG sleeve gastrectomy, RYGB Roux-en-Y gastric bypass, OAGB one anastomosis gastric bypass, BMI body mass index, T2DM Type 2 diabetes mellitus.

a Kruskal-Wallis test.

${ }^{\text {b}}$ Fisher's exact test. 
Table 2. Complications according to primary procedure and CD (Clavien-Dindo) classification system in the full unmatched cohort.

\begin{tabular}{|lcccl} 
Characteristic & \multicolumn{1}{l}{$\begin{array}{l}\text { SG } \\
(\boldsymbol{n}=\mathbf{3 9 8 3})\end{array}$} & $\begin{array}{l}\text { OAGB } \\
(\boldsymbol{n}=\mathbf{7 0 2})\end{array}$ & $\begin{array}{l}\text { RYGB } \\
(\boldsymbol{n}=\mathbf{2 0 8 5})\end{array}$ & $\begin{array}{l}\boldsymbol{p} \\
\text { value }\end{array}$ \\
\hline $\begin{array}{l}\text { All 30-day } \\
\text { complications }\end{array}$ & $233(5.8 \%)$ & $53(7.5 \%)$ & $166(8.0 \%)$ & $0.006^{\text {a }}$ \\
\hline CD 0 & $3750(94.1 \%)$ & $649(92.4 \%)$ & $1919(92.0 \%)$ & - \\
\hline CD 1 & $84(2.1 \%)$ & $11(1.6 \%)$ & $62(3.0 \%)$ & - \\
\hline CD 2 & $63(1.6 \%)$ & $17(2.4 \%)$ & $48(2.3 \%)$ & - \\
\hline CD 3.1 & $16(0.4 \%)$ & $7(1.0 \%)$ & $8(0.4 \%)$ & - \\
\hline CD 3.2 & $50(1.3 \%)$ & $12(1.7 \%)$ & $31(1.5 \%)$ & - \\
\hline CD 4.1 & $13(0.3 \%)$ & $3(0.4 \%)$ & $15(0.7 \%)$ & - \\
\hline CD 4.2 & $3(0.1 \%)$ & 0 & $2(0.1 \%)$ & - \\
\hline CD 5 & $4(0.1 \%)$ & $3(0.4 \%)$ & 0 & $0.016^{\text {a }}$ \\
(Mortality) & & & & \\
\hline
\end{tabular}

$C D$ Clavien-Dindo, SG sleeve gastrectomy, OAGB one anastomosis gastric bypass, RYGB Roux-en-Y gastric bypass.

${ }^{\text {a}}$ Fisher's exact test.

Table 3. Results of multivariate logistic regression on full unmatched cohort.

\begin{tabular}{lll} 
Variable & \multicolumn{2}{l}{ Unmatched patients } \\
\cline { 2 - 3 } & Odds ratio & $\mathbf{9 5 \%} \mathrm{Cl}$ \\
\hline Age & 1.000 & $1.000-1.001$ \\
\hline BMI & 1.000 & $0.999-1.001$ \\
\hline Sex (Male) & 1.011 & $0.997-1.025$ \\
\hline Diabetes (No) & 1.010 & $0.984-1.037$ \\
\hline Diabetes (oral hypoglycaemics) & 0.981 & $0.961-1.000$ \\
\hline Diabetes (insulin) & $1.047^{*}$ & $1.011-1.083$ \\
\hline Hypertension & 1.007 & $0.992-1.022$ \\
\hline Hypercholesterolaemia & $1.024^{*}$ & $1.009-1.040$ \\
\hline Obstructive Sleep Apnoea & 1.012 & $0.998-1.027$ \\
\hline Non-Smoker & $0.984^{*}$ & $0.971-0.998$ \\
\hline White ethnicity & 1.010 & $0.996-1.025$ \\
\hline Other co-morbidity & 1.004 & $0.991-1.017$ \\
\hline Surgery (OAGB) & 1.009 & $0.989-1.030$ \\
\hline Surgery (RYGB) & $1.018^{*}$ & $1.005-1.032$
\end{tabular}

$B M I$ body mass index, OAGB one anastomosis gastric bypass, RYGB Rouxen- $Y$ gastric bypass, $C l$ confidence interval.

*Significant values where $p<0.05$.

\section{0-day morbidity and mortality in the full cohort (unmatched; Table 2)}

The overall complication rate was $6.7 \%(452 / 6770)$ (Table 2). RYGB patients had the highest rate of any complication during the 30 -day follow-up $(8.0 \%$ with RYGB vs $7.5 \%$ for OAGB and $5.8 \%$ for SG $(p=0.006))$. There were seven post-operative mortalities $(0.1 \%$ ) (4 with SG, 3 with OAGB, and nil with RYGB; $p=0.016$; Fisher's exact test).

\section{Multivariate analysis of unmatched cohort (Table 3 )}

On multivariate regression modelling, insulin-dependent T2DM (OR 1.047; 95\% Cl 1.011-1.083), and hypercholesterolaemia (OR 1.024; 95\% Cl 1.009-1.040) (Table 3 and Fig. 1) were associated with increased 30-day complications. Being a non-smoker was associated with reduced complication rates (OR 0.984; $95 \%$ $\mathrm{Cl}$ 0.971-0.998). When compared to SG as the reference category, RYGB, but not OAGB, was associated with an increased rate of 30-day complications (OR 1.018; $95 \% \mathrm{Cl} 1.005-1.032$ for RYGB and OR $1.009 ; 95 \% \mathrm{Cl} 0.989-1.030$ for OAGB).

\section{0-day morbidity and mortality in the propensity score- matched cohort (Tables 4-6)}

SG vs OAGB. In total, 702 pairs were matched with a reduction in SMDs for all matched variables (8/8) (Table 4). The overall complication rate in the SG group was $51(7.3 \%)$ as compared to $53(7.5 \%)$ in the OAGB group (Table 7$)$. The difference was not significant $(p=0.68)$.

SG vs RYGB. In total, 2085 pairs were matched with a reduction in SMDs for seven of the eight matched variables (Table 5). The overall complication rate in the SG group was $127(6.1 \%)$ as compared to $166(7.9 \%)$ in the RYGB group (Table 7). The difference was not significant $(p=0.09)$.

$O A G B$ vs RYGB. In total, 702 pairs were matched with a reduction in SMDs in four of the eight matched variables (4/8) (Table 6). The overall complication rate in both the groups was the same 53 (7.5\%; $p=0.07$; Table 7).

\section{DISCUSSION}

This study shows that there is no significant difference in 30-day morbidity and mortality of SG, RYGB, and OAGB in propensity score-matched cohorts from a large, global dataset collected during the COVID-19 pandemic. Though RYGB was associated with higher 30-day morbidity in comparison with reference SG (OR $1.018 ; 95 \% \mathrm{Cl} 1.005-1.032$ ) in the unmatched cohort on multivariate analysis, the difference disappeared after propensity score matching $(p=0.09)$. In comparison, OAGB was not associated with higher 30-day morbidity in comparison with SG on either multivariate analysis (OR $1.009 ; 95 \% \mathrm{Cl} 0.989-1.030)$ or propensity score-matched comparison ( $p=0.68$ ).

RCTs comparing different bariatric procedures often have weight loss [2] or diabetes control [16] as their endpoints. Some [16] do not even clearly report 30-day morbidity and mortality with different bariatric procedures let alone classifying surgical complications adequately according to the widely used and accepted CD Classification [12]. We cannot, therefore, derive any scientifically valid conclusions regarding complication rates of different procedures from these RCTs.

Outside of RCTs, perceptions regarding relative safety and efficacy of different procedures for different patient groups may introduce potential bias. For example, in this study, we found $33.0 \%$ of patients undergoing OAGB were suffering from T2DM compared to $23.0 \%$ undergoing RYGB and $16.0 \%$ undergoing SG in the unmatched cohorts. This selection bias may be partly accounted for by fact that the randomised studies have shown superior (nonsignificant as they were not powered to evaluate these) outcomes in terms of diabetes improvement with OAGB in comparison with RYGB [2] and with RYGB in comparison with SG [17]. This is important because T2DM is known to be associated with complications after bariatric surgery $[18,19]$ and in our study, Insulin-dependent T2DM was independently associated with 30-day morbidity on multivariate analysis of the unmatched cohort.

Similarly, in the unmatched cohort, hypercholesterolaemia was present in $19.0 \%$ of patients undergoing SG in comparison with $32.0 \%$ of those undergoing OAGB and $23.0 \%$ of those undergoing RYGB. However, after matching, in the analysis of SG and OAGB, the hypercholesterolaemia rates in the two groups were the same at 32.0 and $23.0 \%$ in the analysis of SG and RYGB. This is also important because hypercholesterolaemia was independently associated with 30-day morbidity on multivariate analysis of the unmatched data and differences in hypercholesterolaemia rates in the unmatched cohort may well have accounted for some of the observed differences in 30-day morbidity. Others [20] have also 
Mulitvariate Regression Prior to Matching

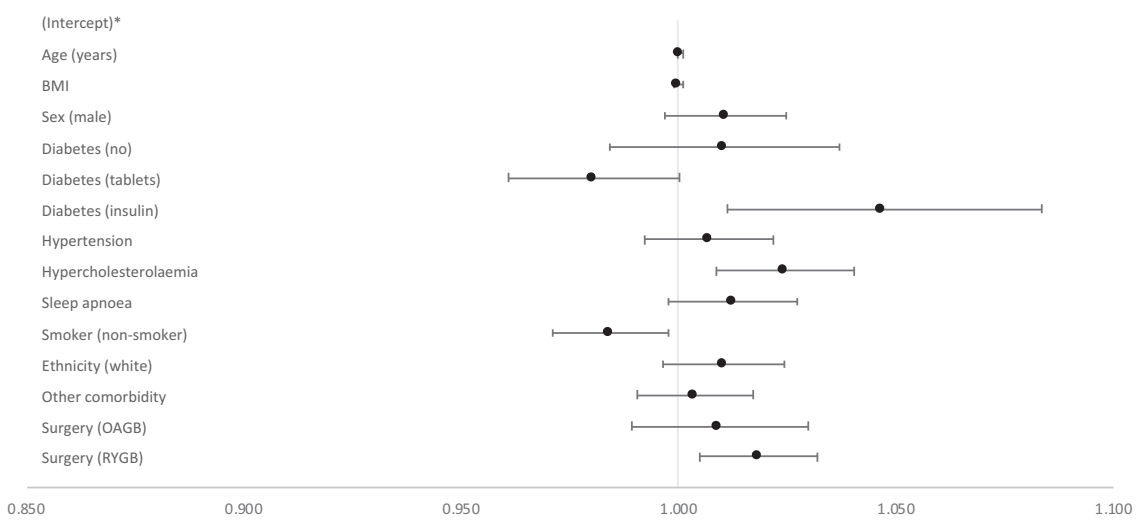

Fig. 1 Multivariate regression results prior to patient matching.

Table 4. A comparison of sleeve gastrectomy (SG) and one anastomosis gastric bypass (OAGB) before and after propensity score matching.

\begin{tabular}{|lcclc} 
Characteristic & SG (702) & OAGB (702) & $\begin{array}{l}\text { Standardised difference } \\
\text { pre-matching (95\% Cl) }\end{array}$ & $\begin{array}{l}\text { Standardised difference } \\
\text { post-matching (95\% Cl) }\end{array}$ \\
\hline Median Age (years) & $40(33-49)$ & $40(33-50)$ & $0.203(0.122-0.283)$ & $0.011(-0.093-0.116)$ \\
\hline Median BMI (kg/m $)$ & $42.87(38.79-48.45)$ & $43.11(38.87-48.77)$ & $0.132(0.052-0.212)$ & $0.017(-0.087-0.122)$ \\
\hline Sex (Female) & $501(71 \%)$ & $496(71 \%)$ & $0.038(-0.042-0.119)$ & $0.016(-0.089-0.12)$ \\
\hline Non-Smoker & $527(75 \%)$ & $528(75 \%)$ & $0.051(-0.029-0.132)$ & $0.003(-0.101-0.108)$ \\
\hline T2DM & $229(33 \%)$ & $229(33 \%)$ & $0.407(0.326-0.488)$ & $0.105-0.105)$ \\
\hline Diet controlled & $74(11 \%)$ & $74(11 \%)$ & & \\
\hline Oral hypoglycaemics & $106(15 \%)$ & $106(15 \%)$ & & $0(-0.105-0.105)$ \\
\hline Insulin therapy & $49(7 \%)$ & $49(7 \%)$ & & $0.006(-0.099-0.11)$ \\
\hline Hypercholesterolaemia & $224(32 \%)$ & $224(32 \%)$ & $0.296(0.215-0.376)$ & $0.003(-0.102-0.108)$ \\
\hline Hypertension & $270(38 \%)$ & $272(39 \%)$ & $0.237(0.157-0.318)$ & \\
\hline Obstructive sleep apnoea & $230(33 \%)$ & $229(33 \%)$ & $0.181(0.101-0.261)$ & \\
\hline
\end{tabular}

SG sleeve gastrectomy, OAGB one anastomsis gastric bypass, T2DM Type 2 diabetes mellitus, $\mathrm{Cl}$ confidence interval.

Table 5. A comparison of sleeve gastrectomy (SG) and Roux-en-Y gastric bypass (RYGB) before and after propensity score matching.

\begin{tabular}{|c|c|c|c|c|}
\hline Characteristic & SG (2085) & RYGB (2085) & $\begin{array}{l}\text { Standardised difference } \\
\text { pre-matching }(95 \% \mathrm{Cl})\end{array}$ & $\begin{array}{l}\text { Standardised difference } \\
\text { post-matching }(95 \% \mathrm{Cl})\end{array}$ \\
\hline Median BMI $\left(\mathrm{kg} / \mathrm{m}^{2}\right)$ & $42.19(38.70-46.14)$ & $41.87(38.67-45.73)$ & $0.096(0.043-0.149)$ & $0.064(0.003-0.125)$ \\
\hline Non-smoker & $1499(72 \%)$ & $1502(72 \%)$ & $0.021(-0.032-0.074)$ & $0.003(-0.058-0.064)$ \\
\hline T2DM & & & $0.215(0.161-0.268)$ & $0.06(-0.001-0.121)$ \\
\hline Insulin therapy & $75(4 \%)$ & $100(5 \%)$ & & \\
\hline Hypercholesterolaemia & $477(23 \%)$ & $476(23 \%)$ & $0.09(0.037-0.143)$ & $0.001(-0.06-0.062)$ \\
\hline Hypertension & $722(35 \%)$ & $720(35 \%)$ & $0.149(0.096-0.202)$ & $0.002(-0.059-0.063)$ \\
\hline Obstructive sleep apnoea & $543(26 \%)$ & $517(25 \%)$ & $0.007(-0.046-0.06)$ & $0.029(-0.032-0.089)$ \\
\hline
\end{tabular}

CD Clavien-Dindo, SG sleeve gastrectomy, RYGB Roux-en-Y gastric bypass, $C l$ confidence interval, BMI body mass index, T2DM Type 2 diabetes mellitus.

found dyslipidaemia to be a predictor of complication after bariatric surgery.

Standardised mean differences in age, BMl, sex, smoking status, hypertension rates all reduced after matching for both the matched comparisons involving SG in this study. Given that all of these characteristics are known to be associated with increased morbidity after bariatric surgery [21-29], differences in these baseline characteristics may have been in part responsible for why the observed difference in morbidity between SG and RYGB or OAGB disappeared after matching. At the same time, and probably because of the fewer number of bypass procedures in the GENEVA database, matching failed to reduce SMDs for age, 
Table 6. A comparison of one anastomosis gastric bypass (OAGB) and Roux-en-Y gastric bypass (RYGB) before and after propensity score matching.

\begin{tabular}{|c|c|c|c|c|c|c|}
\hline & SG $(n=702)$ & OAGB $(n=702)$ & $p$ value $^{a}$ & SG (2085) & RYGB (2085) & $p$ value $^{a}$ \\
\hline $\begin{array}{l}\text { 30-day } \\
\text { complication }\end{array}$ & 51 (7.3\%) & 53 (7.5\%) & 0.68 & 127 (6.1\%) & 166 (7.9\%) & 0.09 \\
\hline CD 0 & 651 (92.7\%) & 649 (92.4\%) & & 1958 (94\%) & 1919 (92\%) & \\
\hline CD 2 & $10(1.4 \%)$ & $17(2.4 \%)$ & & $36(2 \%)$ & $48(2 \%)$ & \\
\hline CD 3.1 & $7(1.0 \%)$ & $7(1.0 \%)$ & & $10(0 \%)$ & $8(0 \%)$ & \\
\hline CD 4.2 & $1(0.1 \%)$ & 0 & & $3(0 \%)$ & $2(0 \%)$ & \\
\hline CD 5 & 2 (0.3\%) & $3(0.4 \%)$ & & $3(0 \%)$ & $0(0 \%)$ & \\
\hline
\end{tabular}

$C D$ Clavien-Dindo, SG sleeve gastrectomy, OAGB one anastomosis gastric bypass, RYGB Roux-en-Y gastric bypass.

${ }^{\text {a } F i s h e r ' s ~ e x a c t ~ t e s t . ~}$

Table 7. Complications in propensity score-matched populations.

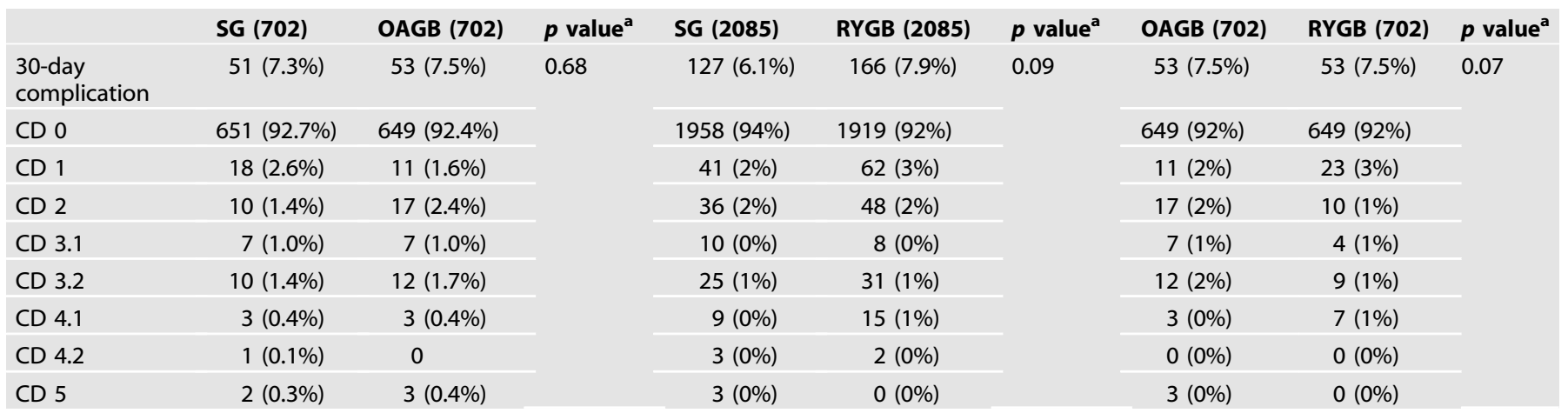

$C D$ Clavien-Dindo, SG sleeve gastrectomy, OAGB one anastomosis gastric bypass, RYGB Roux-en-Y gastric bypass.

${ }^{\text {a }}$ isher's exact test.

sex, smoking status, and hypertension in the comparison between OAGB and RYGB in this study. This may partly account for the observed lack of difference in 30-day morbidity between the two procedures. Future studies on this topic need to be mindful of this.

There is no published study comparing the 30-day morbidity of SG with that of OAGB in propensity score-matched cohorts. This may be due to continued reservations [30] amongst some surgeons about OAGB. Furthermore, and as mentioned above in the Introduction section, there is only one propensity scorematched study [8] in the scientific literature comparing the 30-day safety of OAGB with that of any other procedure (RYGB in this case) and that study only had 279 pairs of OAGB and RYGB. One could argue this is not a large enough sample to study differences in morbidity.

There is only one study [7] in the published literature comparing the 30-day morbidity of SG with that of RYGB. Interestingly that study showed lower complication rates with SG in contrast to our findings. It is however worth noting that these authors do not report standardised mean difference in propensity score-matched populations and given the large numbers matched, it was inevitable that their matching was not perfect with significant difference between the matched populations with regards to important confounding variables such as age, BMl, smoking, insulin-dependent T2DM, etc.

This study represents the first large propensity-matched comparison of 30-day morbidity and mortality of SG, RYGB, and OAGB. This data was collected from a large worldwide collaborative study of real-world bariatric surgical practice. Data completion rates were extremely high with 30-day follow data available for $97.9 \%$ of patients across the entire cohort and this represents a significant strength of this study.

Non-randomised design and self-reported complication rates are two major weaknesses of this study. However, it is not easy to randomise to different procedures with 30-day morbidity as an endpoint and anonymous data collection strategy used in this study may have diminished the desire to under-report complications. Another weakness of this study is that differences in complication rates, though statistically not significant, maybe clinically relevant. Indeed, larger studies may even find statistical significance.

\section{CONCLUSION}

The present analysis shows that there is no significant difference in 30-day morbidity and mortality of SG, OAGB, and RYGB in propensity-matched cohorts.

\section{REFERENCES}

1. Angrisani L, Santonicola A, lovino $P$, Ramos A, Shikora S, Kow L. Bariatric surgery survey 2018: similarities and disparities among the 5 IFSO chapters. Obes Surg.2021;31:1937-48. https://doi.org/10.1007/s11695-020-05207-7.

2. Robert M, Espalieu P, Pelascini E, Caiazzo R, Sterkers A, Khamphommala L, et al. Efficacy and safety of one anastomosis gastric bypass versus Roux-en- $Y$ gastric bypass for obesity (YOMEGA): a multicentre, randomised, open-label, non-inferiority trial. Lancet. 2019;393:1299-309. https://doi.org/10.1016/s01406736(19)30475-1.

3. Salminen $P$, Helmiö $M$, Ovaska J, Juuti $A$, Leivonen $M$, Peromaa-Haavisto $P$, et al. Effect of laparoscopic sleeve gastrectomy vs laparoscopic Roux-en-Y gastric bypass on weight loss at 5 years among patients with morbid obesity: the 
SLEEVEPASS randomized clinical trial. JAMA. 2018;319:241-54. https://doi.org/ 10.1001/jama.2017.20313.

4. Okike N, Payne WS, Neufeld DM, Bernatz PE, Pairolero PC, Sanderson DR. Esophagomyotomy versus forceful dilation for achalasia of the esophagus: results in 899 patients. Ann Thorac Surg. 1979;28:119-25. https://doi.org/10.1016/s00034975(10)63767-8.

5. Alizadeh RF, Li S, Gambhir S, Hinojosa MW, Smith BR, Stamos MJ, et al. Laparoscopic sleeve gastrectomy or laparoscopic gastric bypass for patients with metabolic syndrome: an MBSAQIP analysis. Am Surg. 2019;85:1108-12.

6. Robins JM, Mark SD, Newey WK. Estimating exposure effects by modelling the expectation of exposure conditional on confounders. Biometrics. 1992;48:479-95.

7. Kapur A, Thodiyil P. Primary laparoscopic sleeve gastrectomy versus gastric bypass: a propensity-matched comparison of 30-day outcomes. Surg Obes Relat Dis. 2021;17:1369-82. https://doi.org/10.1016/j.soard.2021.01.022.

8. Docimo S, Yang J, Zhang X, Pryor A, Spaniolas K. One anastomosis gastric bypass versus Roux-en-Y gastric bypass: a 30-day follow-up review. Surg Endosc. 2021. https://doi.org/10.1007/s00464-021-08309-0.

9. Singhal R, Tahrani AA, Ludwig C, Mahawar K. Global 30-day outcomes after bariatric surgery during the COVID-19 pandemic (GENEVA): an international cohort study. Lancet Diabetes Endocrinol. 2021;9:7-9. https://doi.org/10.1016/ s2213-8587(20)30375-2.

10. Singhal R, Ludwig C, Rudge G, Gkoutos GV, Tahrani A, Mahawar K, et al. 30-day morbidity and mortality of bariatric surgery during the COVID-19 pandemic: a multinational cohort study of 7704 patients from 42 countries. Obes Surg. 2021:1-17. https://doi.org/10.1007/s11695-021-05493-9.

11. Singhal R, Wiggins T, Super J, Alqahtani A, Nadler EP, Ludwig C, et al. 30-day morbidity and mortality of bariatric metabolic surgery in adolescence during the COVID-19 pandemic-the GENEVA study. Pediatr Obes. 2021:e12832. https://doi. org/10.1111/ijpo.12832.

12. Dindo D, Demartines N, Clavien PA. Classification of surgical complications: a new proposal with evaluation in a cohort of 6336 patients and results of a survey. Ann Surg. 2004;240:205-13. https://doi.org/10.1097/01.sla.0000133083.54934.ae.

13. Chandra, M. On the generalized distance in statistics. In: Proceedings of the National Institute of Science, India. 2021. Available from: https://www. scienceopen.com/document?vid=a553c5c9-9837-4568-9f20-91 a3f1ca1879.

14. R Core Team. R: A language and environment for statistical computing. R Foundation for Statistical Computing, Vienna, Austria. 2019. https://www.R-project.org/.

15. Stuart EA, King G, Imai K, Ho D. Matchlt: Nonparametric Preprocessing for Parametric Causal Inference. J Stat Softw. 2011;42:28. https://doi.org/10.18637/jss.v042.008.

16. Schauer PR, Kashyap SR, Wolski K, Brethauer SA, Kirwan JP, Pothier CE, et al. Bariatric surgery versus intensive medical therapy in obese patients with diabetes. N Engl J Med. 2012;366:1567-76. https://doi.org/10.1056/NEJMoa1200225.

17. Sharples AJ, Mahawar K. Systematic review and meta-analysis of randomised controlled trials comparing long-term outcomes of Roux-En-Y gastric bypass and sleeve gastrectomy. Obes Surg. 2020;30:664-72. https://doi.org/10.1007/s1 1695019-04235-2.

18. Buchwald H, Estok R, Fahrbach K, Banel D, Sledge I. Trends in mortality in bariatric surgery: a systematic review and meta-analysis. Surgery. 2007;142:621-35.

19. Keidar A. Bariatric surgery for type 2 diabetes reversal: the risks. Diabetes Care. 2011:34:S361-S266.

20. Coblijn UK, Karres J, de Raaff CAL, de Castro SMM, Lagarde SM, van Tets WF, et al. Predicting postoperative complications after bariatric surgery: the Bariatric Surgery Index for Complications, BASIC. Surg Endosc. 2017;31:4438-45. https://doi. org/10.1007/s00464-017-5494-0.

21. Nickel F, de la Garza JR, Werthmann FS, Benner L, Tapking C, Karadza E, et al. Predictors of risk and success of obesity surgery. Obes Facts. 2019;12:427-39. https://doi.org/10.1159/000496939.

22. Qin C, Luo B, Aggarwal A, De Oliveira G, Kim JY. Advanced age as an independent predictor of perioperative risk after laparoscopic sleeve gastrectomy (LSG). Obes Surg. 2015;25:406-12. https://doi.org/10.1007/s11695-014-1462-0.

23. Mocanu V, Dang JT, Switzer N, Madsen K, Birch DW, Karmali S. Sex and race predict adverse outcomes following bariatric surgery: an MBSAQIP analysis. Obes Surg. 2020;30:1093-101. https://doi.org/10.1007/s1 1695-020-04395-6.

24. Husain $F$, Jeong $I H$, Spight $D$, Wolfe B, Mattar SG. Risk factors for early postoperative complications after bariatric surgery. Ann Surg Treat Res. 2018;95:100-10. https://doi.org/10.4174/astr.2018.95.2.100.
25. Vanw MR, Smulders FJ, Luyer MD, Vanm G, Vanhimbeeck FJ, Nienhuijs SW. Predictors for the occurrence of major complications after primary Roux-en-Y gastric bypass surgery. Minerva Chir. 2016;71:286-92.

26. Dayer-Jankechova A, Fournier P, Allemann P, Suter M. Complications after laparoscopic Roux-en-Y gastric bypass in 1573 consecutive patients: are there predictors? Obes Surg. 2016;26:12-20. https://doi.org/10.1007/s11695-015-1752-1.

27. Abraham CR, Werter CR, Ata A, Hazimeh YM, Shah US, Bhakta A, et al. Predictors of hospital readmission after bariatric surgery. J Am Coll Surg. 2015;221:220-7. https://doi.org/10.1016/j.jamcollsurg.2015.02.018.

28. Janik MR, Aryaie AH. The effect of smoking on bariatric surgical 30-day outcomes: propensity-score-matched analysis of the MBSAQIP. Surg Endosc. 2021;35:3905-14. https://doi.org/10.1007/s00464-020-07838-4.

29. Falvo A, Vacharathit V, Kuhn JE, Fluck M, Cunningham RM, Petrick AT, et al. Comparison of short-term outcomes following Roux-en-Y gastric bypass in male and female patients using the MBSAQIP database. Surg Obes Relat Dis. 2020;16:1236-41. https://doi.org/10.1016/j.soard.2020.04.045.

30. Parikh M, Eisenberg D, Johnson J, El-Chaar M. American Society for Metabolic and Bariatric Surgery review of the literature on one-anastomosis gastric bypass. Surg Obes Relat Dis. 2018;14:1088-92. https://doi.org/10.1016/j.soard.2018.04.017.

\section{AUTHOR CONTRIBUTIONS}

Conceptualisation: RS and KM. Data curation: RS, TW, and JS. Data analysis: VRC, GVG, and $\mathrm{CL}$. Tables and figures: RS, VRC, and CL. Manuscript writing and proof reading: all authors.

\section{FUNDING}

This study is funded by Bariatric Unit, University Hospital Birmingham NHS Foundation Trust.

\section{COMPETING INTERESTS}

The authors declare no competing interests.

\section{ADDITIONAL INFORMATION}

Supplementary information The online version contains supplementary material available at https://doi.org/10.1038/s41366-021-01048-1.

Correspondence and requests for materials should be addressed to Rishi Singhal.

Reprints and permission information is available at http://www.nature.com/ reprints

Publisher's note Springer Nature remains neutral with regard to jurisdictional claims in published maps and institutional affiliations.

Open Access This article is licensed under a Creative Commons Attribution 4.0 International License, which permits use, sharing, adaptation, distribution and reproduction in any medium or format, as long as you give appropriate credit to the original author(s) and the source, provide a link to the Creative Commons license, and indicate if changes were made. The images or other third party material in this article are included in the article's Creative Commons license, unless indicated otherwise in a credit line to the material. If material is not included in the article's Creative Commons license and your intended use is not permitted by statutory regulation or exceeds the permitted use, you will need to obtain permission directly from the copyright holder. To view a copy of this license, visit http://creativecommons. org/licenses/by/4.0/.

(c) The Author(s) 2021

\section{GENEVA COLLABORATORS}

Michał Pędziwiatr ${ }^{9}$, Piotr Major ${ }^{9}$, Piotr Zarzycki ${ }^{9}$, Athanasios Pantelis ${ }^{10}$, Dimitris P. Lapatsanis ${ }^{10}$, Georgios Stravodimos ${ }^{10}$, Chris Matthys $^{11}$, Marc Focquet $^{11}$, Wouter Vleeschouwers ${ }^{11}$, Antonio G. Spaventa ${ }^{12}$, Carlos Zerrweck ${ }^{12}$, Antonio Vitiello ${ }^{13}$, Giovanna Berardi ${ }^{13}$, Mario Musella ${ }^{13}$, Alberto Sanchez-Meza ${ }^{14}$, Felipe J. CantuJr ${ }^{14}$, Fernando Mora ${ }^{14}$, Marco A. Cantu ${ }^{14}$, Abhishek Katakwar ${ }^{15}$, D. Nageshwar Reddy ${ }^{15}$, Haitham Elmaleh ${ }^{16}$, Mohammad Hassan ${ }^{16}$, Abdelrahman Elghandour ${ }^{16}$, Mohey Elbanna ${ }^{16}$, Ahmed Osman $^{16}$, 
Athar Khan ${ }^{17}$, Laurent layani ${ }^{17}$, Nalini Kiran ${ }^{17}$, Andrey Velikorechin ${ }^{18}$, Maria Solovyeva ${ }^{18}$, Hamid Melali $^{19}$, Shahab Shahabi ${ }^{19}$ Ashish Agrawal ${ }^{20}$, Apoorv Shrivastava ${ }^{20}$, Ankur Sharma ${ }^{21}$, Bhavya Narwaria ${ }^{21}$, Mahendra Narwaria ${ }^{21}$, Asnat Raziel ${ }^{22}$, Nasser Sakran ${ }^{22}$, Sergio Susmallian ${ }^{22}$, Levent Karagöz ${ }^{23}$, Murat Akbaba ${ }^{23}$, Salih Zeki Pișkin ${ }^{23}$, Ahmet Ziya Balta ${ }^{24}$, Zafer Senol ${ }^{24}$, Emilio Manno ${ }^{25}$, Michele Giuseppe lovino ${ }^{25}$, Ahmed Osman ${ }^{26}$, Mohamed Qassem ${ }^{26}$, Sebastián Arana-Garza ${ }^{27}$, Heitor P. Povoas ${ }^{28}$, Marcos Leão VilasBoas $^{28}$, David Naumann ${ }^{29}$, Alan Li ${ }^{30}$, Basil J. Ammori ${ }^{31}$, Hany Balamoun ${ }^{32}$, Mohammed Salman ${ }^{32}$, Amrit Manik Nasta ${ }^{33}$, Ramen Goel ${ }^{33}$, Hugo Sánchez-Aguilar ${ }^{34}$, Miguel F. Herrera ${ }^{34}$, Adel Abou-mrad ${ }^{35}$, Lucie Cloix ${ }^{35}$, Guilherme Silva Mazzini ${ }^{36}$, Leonardo Kristem ${ }^{36}$, Andre Lazaro ${ }^{37}$, Jose Campos ${ }^{37}$, Joaquín Bernardo ${ }^{38}$, Jesús González ${ }^{38}$, Carlos Trindade ${ }^{39}$, Octávio Viveiros ${ }^{39}$, Rui Ribeiro ${ }^{39}$, David Goitein ${ }^{40}$, David Hazzan ${ }^{40}$, Lior Segev ${ }^{40}$, Tamar Beck ${ }^{40}$, Hernán Reyes ${ }^{41}$, Jerónimo Monterrubio ${ }^{41}$, Paulina García ${ }^{41}$, Marine Benois ${ }^{42}$, Radwan Kassir ${ }^{42}$, Alessandro Contine ${ }^{43}$, Moustafa Elshafei ${ }^{44}$, Sueleyman Aktas ${ }^{44}$, Sylvia Weiner ${ }^{44}$, Till Heidsieck ${ }^{44}$, Luis Level $^{45}$, Silvia Pinango ${ }^{45}$, Patricia Martinez Ortega ${ }^{46}$, Rafael Moncada ${ }^{46}$, Victor Valenti ${ }^{46}$, Ivan Vlahović ${ }^{47}$, Zdenko Boras ${ }^{47}$, Arnaud Liagre $^{48}$, Francesco Martini ${ }^{48}$, Gildas Juglard ${ }^{48}$, Manish Motwani ${ }^{49}$, Sukhvinder Singh Saggu ${ }^{49}$, Hazem Al Momani ${ }^{50}$, Luis Adolfo Aceves López ${ }^{51}$, María Angelina Contreras Cortez ${ }^{51}$, Rodrigo Aceves Zavala ${ }^{51}$, Christine D'Haese RN ${ }^{52}$, Ivo Kempeneers ${ }^{52}$, Jacques Himpens ${ }^{52}$, Andrea Lazzati ${ }^{53}$, Luca Paolino ${ }^{53}$, Sarah Bathaei ${ }^{53}$, Abdulkadir Bedirli ${ }^{54}$, Aydın Yavuz ${ }^{54}$, Çağr Büyükkasap ${ }^{54}$, Safa Özaydın ${ }^{54}$, Andrzej Kwiatkowski ${ }^{55}$, Katarzyna Bartosiak ${ }^{55}$, Maciej Walędziak ${ }^{55}$, Antonella Santonicola ${ }^{56}$, Luigi Angrisani ${ }^{56}$, Paola lovino ${ }^{56}$, Rossella Palma ${ }^{56}$, Angelo lossa ${ }^{57}$, Cristian Eugeniu Boru ${ }^{57}$, Francesco De Angelis ${ }^{57}$, Gianfranco Silecchia ${ }^{57}$, Abdulzahra Hussain ${ }^{58}$, Srivinasan Balchandra ${ }^{58}$, Izaskun Balciscueta Coltell ${ }^{59}$, Javier Lorenzo Pérez ${ }^{59}$, Ashok Bohra ${ }^{60}$, Altaf K. Awan ${ }^{60}$, Brijesh Madhok ${ }^{60}$, Paul C. Leeder ${ }^{60}$, Sherif Awad ${ }^{60}$, Waleed Al-Khyatt ${ }^{60}$, Ashraf Shoma ${ }^{61}$, Hosam Elghadban ${ }^{61}$, Sameh Ghareeb ${ }^{61}$, Bryan Mathews ${ }^{62}$, Marina Kurian ${ }^{62}$, Andreas Larentzakis ${ }^{63}$, Gavriella Zoi Vrakopoulou ${ }^{63}$, Konstantinos Albanopoulos ${ }^{63}$, Ahemt Bozdag ${ }^{64}$, Azmi Lale ${ }^{64}$, Cuneyt Kirkil ${ }^{64}$, Mursid Dincer ${ }^{64}$, Ahmad Bashir ${ }^{65}$, Ashraf Haddad ${ }^{65}$, Leen Abu Hijleh ${ }^{65}$, Bruno Zilberstein ${ }^{66}$, Danilo Dallago de Marchi ${ }^{66}$, Willy Petrini Souza ${ }^{66}$, Carl Magnus Brodén ${ }^{67}$, Hjörtur Gislason ${ }^{67}$, Kamran Shah ${ }^{67}$, Antonio Ambrosi ${ }^{68}$, Giovanna Pavone ${ }^{68}$, Nicola Tartaglia ${ }^{68}$, S. Lakshmi Kumari Kona ${ }^{69}$, K. Kalyan ${ }^{69}$, Cesar Ernesto Guevara Perez ${ }^{70}$, Miguel Alberto Forero Botero ${ }^{70}$, Adrian Covic ${ }^{71}$, Daniel Timofte ${ }^{71}$, Madalina Maxim ${ }^{71}$, Dashti Faraj ${ }^{72}$, Larissa Tseng ${ }^{72}$, Ronald Liem ${ }^{72}$, Gürdal Ören ${ }^{73}$, Evren Dilektasli ${ }^{74}$, Ilker Yalcin ${ }^{74}$, Hudhaifa AlMukhtar ${ }^{75}$, Mohammed Al Hadad ${ }^{75}$, Rasmi Mohan ${ }^{75}$, Naresh Arora ${ }^{76}$, Digvijaysingh Bedi ${ }^{76}$, Claire Rives-Lange ${ }^{77}$, Jean-Marc Chevallier ${ }^{77}$, Tigran Poghosyan ${ }^{77}$, Hugues Sebbag ${ }^{78}$, Lamia Zinaï ${ }^{78}$, Saadi Khaldi ${ }^{78}$, Charles Mauchien ${ }^{79}$, Davide Mazza ${ }^{79}$, Georgiana Dinescu ${ }^{79}$, Bernardo Rea ${ }^{80}$, Fernando Pérez-Galaz ${ }^{80}$, Luis Zavala ${ }^{81}$, Anais Besa ${ }^{82}$, Anna Curell ${ }^{82}$, Jose M. Balibrea ${ }^{82}$, Carlos Vaz ${ }^{83}$, Luis Galindo ${ }^{83}$, Nelson Silva ${ }^{83}$, José Luis Estrada Caballero ${ }^{84}$, Sergio Ortiz Sebastian ${ }^{84}$, João Caetano Dallegrave Marchesini ${ }^{85}$, Ricardo Arcanjo da Fonseca Pereira ${ }^{85}$, Wagner Herbert Sobottka ${ }^{85}$, Felipe Eduardo Fiolo ${ }^{86}$, Matias Turchi ${ }^{86}$, Antonio Claudio Jamel Coelho ${ }^{87}$, Andre Luis Zacaron ${ }^{87}$, André Barbosa ${ }^{88}$, Reynaldo Quinino ${ }^{88}$, Gabriel Menaldi ${ }^{89}$, Nicolás Paleari ${ }^{89}$, Pedro Martinez-Duartez ${ }^{89}$, Gabriel Martínez de Aragon Ramírez de Esparza ${ }^{90}$, Valentin Sierra Esteban ${ }^{90}$, Antonio Torres ${ }^{91}$, Jose Luis Garcia-Galocha ${ }^{91}$, Miguel Josa ${ }^{91}$, Jose Manuel Pacheco-Garcia92, Maria Angeles Mayo-Ossorio ${ }^{92}$, Pradeep Chowbey ${ }^{93}$, Vandana Soni ${ }^{93}$, Hercio Azevedo de Vasconcelos Cunha ${ }^{94}$, Michel Victor Castilho ${ }^{94}$,

Rafael Meneguzzi Alves Ferreira ${ }^{94}$, Thiago Alvim Barreiro ${ }^{94}$, Alexandros Charalabopoulos ${ }^{95}$, Elias Sdralis ${ }^{95}$, Spyridon Davakis ${ }^{95}$, Benoit Bomans ${ }^{96}$, Giovanni Dapri ${ }^{96}$, Koenraad Van Belle ${ }^{96}$, Mazen Takieddine ${ }^{97}$, Pol Vaneukem ${ }^{97}$, Esma Seda Akalın Karaca ${ }^{98}$, Fatih Can Karaca ${ }^{98}$, Aziz Sumer $^{99}$, Caghan Peksen ${ }^{99}$, Osman Anil Savas ${ }^{99}$, Elias Chousleb ${ }^{100}$, Fahad Elmokayed ${ }^{101}$, Islam Fakhereldin ${ }^{101}$, Hany Mohamed Aboshanab ${ }^{101}$, Talal Swelium ${ }^{101}$, Ahmad Gudal ${ }^{102}$, Lamees Gamloo ${ }^{102}$, Ayushka Ugale ${ }^{103}$, Surendra Ugale ${ }^{103}$, Clara Boeker ${ }^{104}$, Christian Reetz ${ }^{104}$, Ibrahim Ali Hakami ${ }^{104}$, Julian Mall ${ }^{104}$, Andreas Alexandrou ${ }^{105}$, Efstratia Baili ${ }^{105}$, Zsolt Bodnar ${ }^{106}$ Almantas Maleckas ${ }^{107}$, Rita Gudaityte ${ }^{107}$, Cem Emir Guldogan ${ }^{108}$, Emre Gundogdu ${ }^{108}$, Mehmet Mahir Ozmen ${ }^{108}$, Deepti Thakkar ${ }^{109}$, Nandakishore Dukkipati ${ }^{109}$, Poonam Shashank Shah ${ }^{110}$, Shashank Subhashchandra Shah ${ }^{110}$, Simran Shashank Shah ${ }^{110}$, Md Tanveer Adil ${ }^{111}$, Periyathambi Jambulingam ${ }^{111}$, Ravikrishna Mamidanna ${ }^{111}$, Douglas Whitelaw ${ }^{112}$, Md Tanveer Adil ${ }^{112}$, Vigyan Jain ${ }^{112}$, Deepa Kizhakke Veetil ${ }^{113}$, Randeep Wadhawan ${ }^{113}$, Antonio Torres ${ }^{114}$, Max Torres ${ }^{114}$, Tabata Tinoco ${ }^{114}$, Wouter Leclercq ${ }^{115}$, Marleen Romeijn ${ }^{115}$, Kelly van de Pas ${ }^{115}$, Ali K. Alkhazraji ${ }^{116}$, Safwan A. Taha ${ }^{116}$, Murat Ustun ${ }^{117}$ ', Taner Yigit ${ }^{117}$, Aatif Inam ${ }^{118}$, Muhammad Burhanulhaq ${ }^{118}$, Abdolreza Pazouki ${ }^{119}$, Foolad Eghbali ${ }^{119}$, Mohammad Kermansaravi ${ }^{119}$, Amir Hosein Davarpanah Jazi ${ }^{120}$, Mohsen Mahmoudieh ${ }^{120}$, Neda Mogharehabed ${ }^{120}$, Gregory Tsiotos ${ }^{121}$, Konstantinos Stamou ${ }^{121}$, Francisco J. Barrera Rodriguez ${ }^{122}$, Marco A. Rojas Navarro ${ }^{122}$, Omar Mohamed Torres ${ }^{122}$, Sergio Lopez Martinez ${ }^{122}$, Elda Rocio Maltos Tamez ${ }^{123}$, Gustavo A. Millan Cornejo ${ }^{123}$, Jose Eduardo Garcia Flores ${ }^{123}$, Diya Aldeen Mohammed ${ }^{124}$, Mohamad Hayssam Elfawal ${ }^{124}$, Asim Shabbir ${ }^{125}$, Kim Guowei ${ }^{125}$, Jimmy By So ${ }^{125}$, Elif Tuğçe Kaplan ${ }^{126}$, Mehmet Kaplan ${ }^{126}$, Tuğba Kaplan ${ }^{126}$, DangTuan Pham ${ }^{127}$, Gurteshwar Rana ${ }^{127}$, Mojdeh Kappus ${ }^{127}$, Riddish Gadani ${ }^{128}$, Manish Kahitan ${ }^{128}$, Koshish Pokharel ${ }^{128}$, Alan Osborne ${ }^{129}$, Dimitri Pournaras ${ }^{129}$, James Hewes ${ }^{129}$, Errichetta Napolitano ${ }^{130}$, Sonja Chiappetta ${ }^{130}$, Vincenzo Bottino ${ }^{130}$, Evelyn Dorado ${ }^{131}$, Axel Schoettler ${ }^{132}$, Daniel Gaertner ${ }^{132}$, Katharina Fedtke ${ }^{132}$, Francisco Aguilar-Espinosa ${ }^{133}$, Saul Aceves-Lozano ${ }^{133}$, Alessandro Balani ${ }^{134}$, Carlo Nagliati ${ }^{134}$, Damiano Pennisi ${ }^{134}$, Andrea Rizzi ${ }^{135}$, Francesco Frattini ${ }^{135}$, Diego Foschi ${ }^{136}$, Laura Benuzzi ${ }^{136}$, Chirag Parikh ${ }^{137}$, Harshil Shah ${ }^{137}$, Enrico Pinotti ${ }^{138}$, Mauro Montuori ${ }^{138}$, Vincenzo Borrelli ${ }^{138}$, Jerome Dargent ${ }^{139}$, Catalin A. Copaescu ${ }^{140}$, Ionut Hutopila ${ }^{140}$, Bogdan Smeu ${ }^{140}$, Bart Witteman ${ }^{141}$, Eric Hazebroek ${ }^{141}$, Laura Deden ${ }^{141}$, Laura Heusschen ${ }^{141}$, Sietske Okkema ${ }^{141}$, Theo Aufenacker ${ }^{141}$, Willem den Hengst ${ }^{141}$, Wouter Vening ${ }^{141}$, Yonta van der Burgh ${ }^{141}$, Ahmad Ghazal ${ }^{142}$, Hamza Ibrahim ${ }^{142}$, Mourad Niazi ${ }^{142}$, Bilal Alkhaffaf ${ }^{143}$, Mohammad Altarawni ${ }^{143}$, Giovanni Carlo Cesana ${ }^{144}$, Marco Anselmino ${ }^{144}$, Matteo Uccelli ${ }^{144}$, Stefano Olmi ${ }^{144}$, Christine Stier ${ }^{145}$, Tahsin Akmanlar ${ }^{145}$, Thomas Sonnenberg ${ }^{146}$, Uwe Schieferbein ${ }^{146}$, Alejandro Marcolini ${ }^{147}$, Diego Awruch ${ }^{147}$, Marco Vicentin ${ }^{147}$, Eduardo Lemos de Souza Bastos ${ }^{148}$, Samuel Azenha Gregorio ${ }^{148}$, Anmol Ahuja ${ }^{149}$, Tarun Mittal ${ }^{149}$, Roel Bolckmans ${ }^{150}$, Tom Wiggins ${ }^{150}$, Clément Baratte ${ }^{151}$, Judith Aron Wisnewsky ${ }^{151}$, Laurent Genser ${ }^{151}$, Lynn Chong ${ }^{152}$, Lillian Taylor ${ }^{152}$, Salena Ward ${ }^{152}$, Lynn Chong ${ }^{152}$, Lillian Taylor ${ }^{152}$, Michael W. $\mathrm{Hi}^{152}$, Helen Heneghan ${ }^{153}$, Naomi Fearon ${ }^{153}$, Andreas Plamper ${ }^{154}$, Karl Rheinwalt ${ }^{154}$, Helen Heneghan ${ }^{153}$, Justin Geoghegan ${ }^{153}$, Kin Cheung Ng ${ }^{153}$, Naomi Fearon ${ }^{153}$, Krzysztof Kaseja ${ }^{155}$, Maciej Kotowski ${ }^{155}$, Tarig A. Samarkandy ${ }^{156}$, Adolfo Leyva-Alvizo ${ }^{157}$, Lourdes Corzo-Culebro ${ }^{157}$, Cunchuan Wang ${ }^{158}$, Wah Yang ${ }^{158}$, Zhiyong Dong ${ }^{158}$, Manel Riera ${ }^{159}$, Rajesh Jain ${ }^{159}$, 
Hosam Hamed ${ }^{160}$, Mohammed Said ${ }^{160}$, Katia Zarzar ${ }^{161}$, Manuel Garcia ${ }^{161}$, Ahmet Gökhan Türkçapar ${ }^{162}$, Ozan Șen ${ }^{162}$, Edoardo Baldini ${ }^{163}$, Luigi Conti $^{163}$, Cacio Wietzycoski ${ }^{164}$, Eduardo Lopes ${ }^{164}$, Tadeja Pintar ${ }^{165}$, Jure Salobir ${ }^{165}$, Cengiz Aydin ${ }^{166}$, Semra Demirli Atici ${ }^{166}$, Anıl Ergin ${ }^{167}$, Huseyin Ciyiltepe ${ }^{167}$, Mehmet Abdussamet Bozkurt ${ }^{168}$, Mehmet Celal Kizilkaya ${ }^{168}$, Nezihe Berrin Dodur Onalan ${ }^{168}{ }^{\prime}$ Mariana Nabila Binti Ahmad Zuber ${ }^{169}$, Wei Jin Wong ${ }^{169}$, Amador Garcia ${ }^{170}$, Laura Vidal ${ }^{170}$, Marc Beisani ${ }^{170}$, Jorge Pasquier ${ }^{171}$, Ramon Vilallonga ${ }^{171}$, Sharad Sharma ${ }^{172}$, Chetan Parmar ${ }^{173}$, Lyndcie Lee ${ }^{173}$, Pratik Sufi ${ }^{173}$, Hüseyin Sinan ${ }^{174}$ and Mehmet Saydam ${ }^{175}$

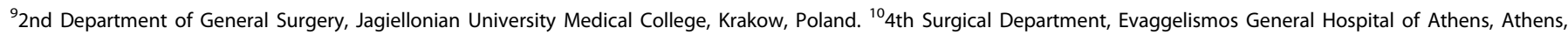
Greece. ${ }^{11} \mathrm{AZ}$ Sint Elisabeth Zottegem, Zottegem, Belgium. ${ }^{12} \mathrm{ABC}$ Medical Center Santa Fe, Mexico City, Mexico. ${ }^{13}$ Advanced Biomedical Sciences Department, Naples "Federico II" University, Naples, Italy. ${ }^{14}$ Advanced Medicine Institute, Reynosa, Mexico. ${ }^{15}$ AIG Hospital, Hyderabad, India. ${ }^{16}$ Ain Shams University Hospitals, Cairo, Egypt. ${ }^{17}$ Al Shark Hospital,

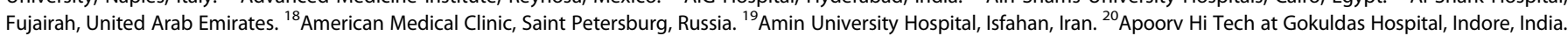

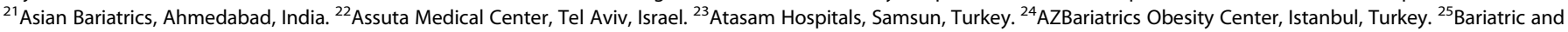
Metabolic Surgery Unit, Ospedale A. Cardarelli, Naples, Italy. ${ }^{26}$ Bariatric Surgery Department, Faculty of Medicine, Ain Shams University, Cairo, Egypt. ${ }^{27}$ Bariatric Surgery Experts, Monterrey, Mexico. ${ }^{28}$ BAROS-Bariatric and Metabolic Surgery, Salvador, Brazil. ${ }^{29}$ Birmingham Heartlands Hospital, University Hospital Birmingham NHS Foundation Trust, Birmingham, UK. ${ }^{30} \mathrm{BMI}$ Alexandra Hospital, Manchester, UK. ${ }^{31}$ Burjeel Hospital, Abu Dhabi, United Arab Emirates. ${ }^{32}$ Cairo University, Cairo, Egypt. ${ }^{33}$ Center of Metabolic Surgery, Wockhardt Hospital, Agripada, Mumbai, India. ${ }^{34}$ Center of Nutrition and Obesity, ABC Medical Center (Observatorio), Mexico City, Mexico. ${ }^{35}$ Centre Hospitalier Regional d'ORLEANS, Orléans, France. ${ }^{36}$ Centro de Obesidade do Instituto do Aparelho Digestivo, Porto Alegre, Brazil. ${ }^{37}$ Centro Hospitalar e Universitario de Coimbra, Coimbra, Portugal. ${ }^{38}$ Centro Médico de Asturias, Oviedo, Spain. ${ }^{39}$ Centro Multidisciplinar da Doença Metabólica, Clínica Santo Antonio, Lusiadas, Amadora, Portugal. ${ }^{40}$ Chaim Sheba Medical Center, Affiliated with Sackler School of Medicine, Tel Aviv University, Ramat Gan, Israel. ${ }^{41}$ Christus Muguerza Sur, Monterrey, Mexico. ${ }^{42} \mathrm{CHU}$ Félix Guyon, la Réunion, Réunion, France. ${ }^{43}$ Città di Castello Hospital, Usl Umbria 1, Città di Castello, Italy. ${ }^{44}$ Clinic for Metabolic Surgery, Krankenhaus Nordwest, Frankfurt, Germany. ${ }^{45}$ Clínica Santa Sofía, Caracas, Venezuela. ${ }^{46}$ Clinica Universidad de Navarra, Pamplona, Spain. ${ }^{47} \mathrm{Clinical}$ Hospital Centre Osijek, Osijek, Croatia. ${ }^{48} \mathrm{Clinique}$ des Cedres, Cornebarrieu, France. ${ }^{49} \mathrm{COMS}$, Apollo

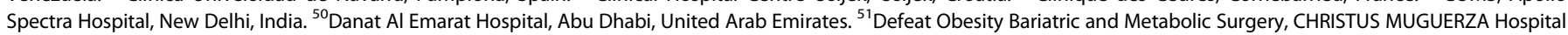
Reynosa, Reynosa, TAMPS, Mexico. ${ }^{52}$ Delta CHIREC Hospital, Brussels, Belgium. ${ }^{53}$ Department of General Surgery, Center Hospitalier Intercommunal de Créteil, Paris, France. ${ }^{54}$ Department of General Surgery, Gazi University Faculty of Medicine, Yenimahalle/Ankara, Turkey. ${ }^{55}$ Department of General Surgery, Military Institute of Medicine, Szaserów 128 , 04-141 Warsaw, Poland. ${ }^{56}$ Department of Public Health, "Federico II" University of Naples, Naples, Italy. ${ }^{57}$ Division of General Surgery and Bariatric Center of Excellence IFSO-EC, University La Sapienza of Rome, Rome, Italy. ${ }^{58}$ Doncaster and Bassetlaw Teaching Hospitals, Yorkshire, UK. ${ }^{59}$ Dr. Lorenzo, Innovación Cirugía Obesidad y Diabetes, Valencia, Spain. ${ }^{60}$ East-Midlands Bariatric and Metabolic Institute (EMBMI), Royal Derby Hospital, Derby, UK. ${ }^{61}$ Elsafa Private Hospital and Mansoura University Hospital and Eldelta Hospital, Mansoura, Egypt. ${ }^{62} \mathrm{New}$ York Minimally Invasive Surgery PLLC, New York, NY, USA. ${ }^{63}$ First Department of Propaedeutic Surgery, Hippocration General Athens Hospital, National and Kapodistrian University of Athens, Athens, Greece. ${ }^{64}$ Fırat University Hospital, Elazığ, Turkey. ${ }^{65}$ Gastrointestinal, Bariatric and Metabolic Center at Jordan Hospital, Amman, Jordan. ${ }^{66}$ GASTROMED-Zilberstein Institute, Sao Paulo, Brazil. ${ }^{67} \mathrm{~GB}$ Obesitas Skaane, Malmö, Sweden. ${ }^{68}$ General Surgery, University of Foggia, Foggia, Italy. ${ }^{69}$ Glenagles Global Hospital, Lakdikapul, Hyderabad, India. ${ }^{70}$ Grammo SAS IPS, Bogotá, Colombia. ${ }^{71}$ Grigore T. Popa University of Medicine and Pharmacy, lasi, Romania. ${ }^{72}$ Groene Hart Hospital in Gouda and Dutch Obesity Clinic, The Hague, The Netherlands. ${ }^{73}$ Gürdal Ören Bariatric Surgery Center, İstanbul, Turkey. ${ }^{74}$ Hayat Hospital, General Surgery, Bariatric and Metabolic Surgery, Bursa, Turkey. ${ }^{75}$ Healthpoint Hospital, Abu Dhabi, United Arab Emirates. ${ }^{76}$ Hope Obesity Centre, Ahmedabad, India. ${ }^{77}$ Hôpital Européen Georges Pompidou, AP-HP, Université de Paris, Paris, France. ${ }^{78}$ Hôpital Privé de Provence (HPP), Aix-en-Provence, France. ${ }^{79}$ Hôpital Ste Musse Centre Hospitalier, Toulon, France. ${ }^{80}$ Hospital Ángeles Lomas, Estado de México, México. ${ }^{81}$ Hospital Christus Muguerza Sur, Monterrey, México. ${ }^{82}$ Hospital Clínic de Barcelona, Barcelona, Spain. ${ }^{83}$ Hospital CUF Tejo, Lisbon, Portugal. ${ }^{84}$ Hospital General Universitario Alicante Spain, Alicante, Spain. ${ }^{85} \mathrm{Hospital}$ Marcelino Champagnat, Curitiba, Brazil. ${ }^{86} \mathrm{Hospital}$ Privado de Comunidad, Mar del Plata, Argentina. ${ }^{87} \mathrm{Hospital}$ Rios D'Or, Rio de Janeiro, Brazil. ${ }^{88} \mathrm{Hospital}$ Unimed Natal, Natal, Brazil. ${ }^{89} \mathrm{Hospital}$ Universitario Austral, Bariatric and Metabolic Department, Buenos Aires, Argentina. ${ }^{90}$ Hospital Universitario de Álava, Vitoria-Gasteiz, Spain. ${ }^{91}$ Hospital Universitario Madrid Monteprincipe, Hospital Clinico San Carlos, Madrid, Spain. ${ }^{92}$ Hospital Universitario Puerta del Mar, Cadiz, Spain. ${ }^{93}$ Institute of Minimal Access, Metabolic and Bariatric Surgery, Max Super-Speciality Hospital, Saket, New Delhi, India. ${ }^{94}$ Instituto Campineiro de Tratamento da

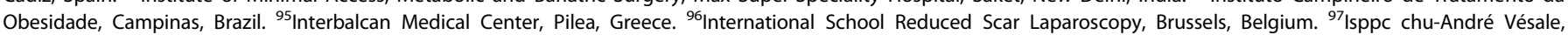
Metabolic and Bariatric Surgery, Montigny-le-Tilleul, Belgium. ${ }^{98}$ Istanbul Bilgi University,Turkey (first author), Department of Pulmonary Medicine, Istanbul Yedikule Chest Diseases and Thoracic Surgery Education and Research Hospital (second author), Zeytinburnu, Turkey. ${ }^{99}$ Istinye University, School of Medicine, Istanbul, Turkey. ${ }^{100}$ Jackson North Medical

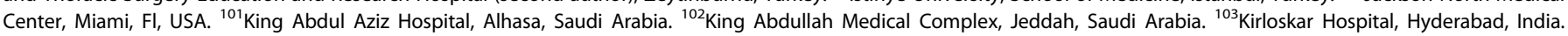
${ }^{104}$ Klinikum Region Hannover-Klinikum Nordstadt, Hannover, Germany. ${ }^{105}$ Laiko General Hospital, National and Kapodistrian University of Athens, Athens, Greece. ${ }^{106}$ Letterkenny University Hospital, Letterkenny, Ireland. ${ }^{107}$ Lithuanian University of Health Sciences, Surgery Department, Kaunas, Lithuania. ${ }^{108}$ Liv Hospital Ankara, Ankara, Turkey. ${ }^{109}$ Livlife

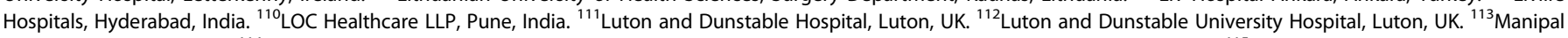
Hospital, New Delhi, India. ${ }^{114}$ Max Medical, Centro de Cirugía Bariátrica/Robótica, Hospital Metropilitano de Quito/Ecuador, Quito, Ecuador. ${ }^{115}$ Máxima Medical Center, Veldhoven, The Netherlands. ${ }^{116}$ Mediclinic Hospital Airport Road, Abu Dhabi, United Arab Emirates. ${ }^{117}$ Memorial Hospital, Istanbul, Turkey. ${ }^{118}$ Metabolic, Thoracic and General Surgery Team

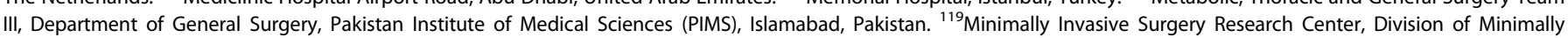
Invasive and Bariatric Surgery, Department of Surgery, Rasool-e Akram Hospital, Iran University of Medical Sciences, Tehran, Iran. ${ }^{120}$ Minimally Invasive Surgery Research Center, Isfahan University of Medical Sciences, Isfahan, Iran. ${ }^{121}$ MITERA Hospital, Athens, Greece. ${ }^{122}$ Monterrey Gastro and Bariatric Group, Monterrey, Mexico. ${ }^{123}$ MtyBariatrics, Monterrey,

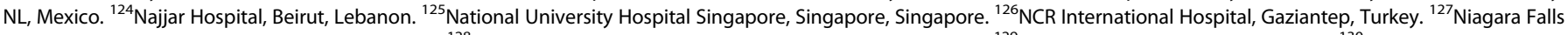

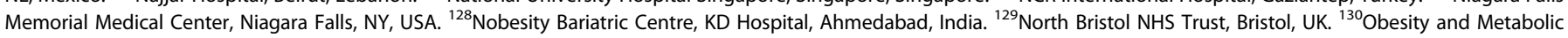

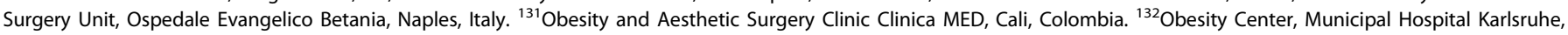

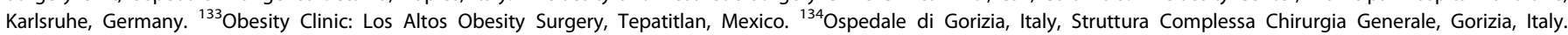
${ }^{135}$ Ospedale Galmarini Tradate, Varese, Italy. ${ }^{136}$ Ospedale San Giuseppe IRCCS Multimedica, University of Milan, Milan, Italy. ${ }^{137}$ Parul Institute of Medical Sciences and Research,

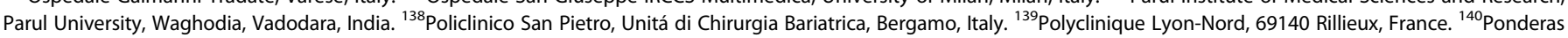

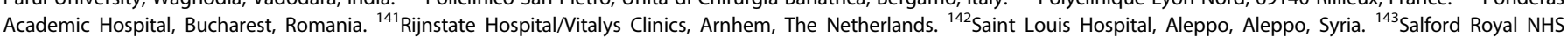
Foundation Trust, Salford, UK. ${ }^{144}$ San Marco Hospital GSD, Zingonia, BG, Italy. ${ }^{145}$ Sana Obesity Center Northrhine Westphalia, Clinic for General, Visceral, and Transplantation Surgery, RWTH University Aachen, Aachen, Germany. ${ }^{146}$ Sana Obesity Center Northrhine Westphalia, Westphalia, Germany. ${ }^{147}$ Sanatorio Britanico de Rosario, Rosario, Santa Fe,

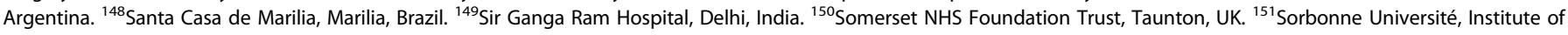
Cardiometabolism and Nutrition ICAN, Assistance Publique-Hôpitaux de Paris, Departments of Digestive surgery and Nutrition, Pitié-Salpêtrière University Hospital, Paris, France.

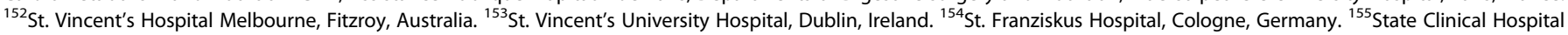

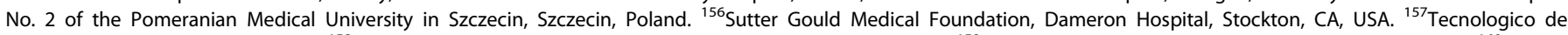
Monterrey, Monterrey, MX, Mexico. ${ }^{158}$ The First Affiliated Hospital of Jinan University, Guangzhou, China. ${ }^{159}$ The Shrewsbury and Telford Hospital, Shrewsbury, UK. ${ }^{160}$ Truelife Bariatric and Digestive Surgery Center, Mansoura, Dakahleyya, Egypt. ${ }^{161}$ Tu Opcion Bariatrica, Monterrey, Mexico. ${ }^{162}$ Türkçapar Bariatrics Obesity Center, İstanbul, Turkey. ${ }^{163}$ U.O. Chirurgia, Ospedale "Guglielmo da Saliceto", Piacenza, Italy. ${ }^{164}$ Unimed Vale do Caí Hospital, Montenegro, BR. Maicé Hospital, Caçador, BR, Brazil. ${ }^{165}$ University Medical Center

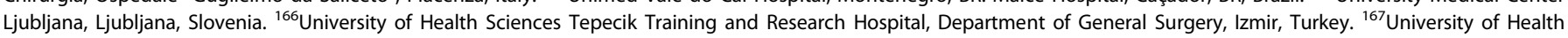

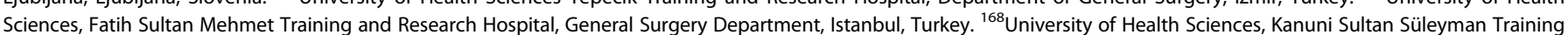
and Research Hospital, Istanbul, Turkey. ${ }^{169}$ University of Malaya Medical Centre, Kuala Lumpur, Malaysia. ${ }^{170}$ Vall d'Hebron University Hospital, Barcelona, Spain. ${ }^{171}$ Vall Hebron

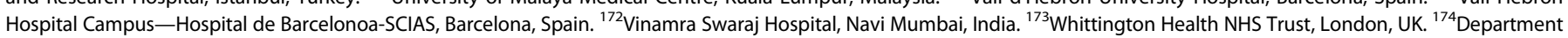
of Metabolic Surgery, Special Etiler Hospital, Istanbul, Turkey. ${ }^{175}$ Department of General Surgery, Diskapi Yildirim Beyazit Training and Research Hospital, Ankara, Turkey. 